\title{
The relationship between apolipoprotein genes polymorphisms and susceptibility to osteonecrosis of the femoral head: a meta- analysis
}

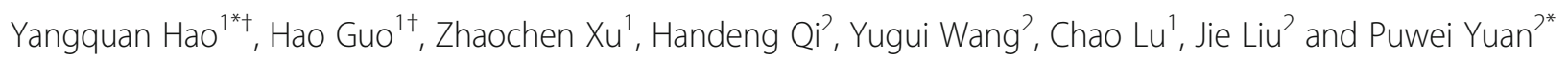

\begin{abstract}
Background: The objective of this study was to evaluate whether apolipoprotein gene polymorphisms confer susceptibility to osteonecrosis of the femoral head (ONFH).

Methods: The relevant literature was screened from databases of Pubmed, Embase, Wanfang, Weipu and China National Knowledge Internet (CNKI) until May, 2017. In addition, odds ratio (OR) and its corresponding 95\% confidence interval $(\mathrm{Cl})$ were used as a measure of effect size for calculating effect size.

Results: Totally, six case-control studies were included in this meta-analysis. It revealed that ApoB-C7623T polymorphism frequency was increased in ONFH group than in control group under three genetic models, including allele model ( $T$ vs. C, OR $=4.5149,95 \%$ Cl: 1.6968-12.0134); additive model (TC vs. CC, OR=6.2515, 95\% Cl: 2.0939-18.6640); and dominant model (TT + TC vs. CC, OR $=5.4998,95 \% \mathrm{Cl}: 1.9246-15.7163)$. In addition, the increased risk of ONFH were related to ApoA1-rs1799837 polymorphism under additive model (AA vs. GG, OR=1. 4175, 95\% Cl: 1.0522-1.9096) and recessive model (AA vs. GG + AG, OR=1.7727, 95\% Cl: 1.3399-2.3452). However, four ApoB rs1042031, rs693, 3'-VNTR and G12619A polymorphisms under the all genetic models were not associated with susceptibility to ONFH.
\end{abstract}

Conclusion: The T allele and TC genotype of ApoB-C7623T and AA genotype of ApoA1-rs1799837 may contribute to increase the risk of ONFH.

Keywords: Osteonecrosis of the femoral head, Apolipoprotein A1, Apolipoprotein B, Polymorphism, Genetic model, Meta-analysis

\section{Background}

Osteonecrosis of the femoral head (ONFH) is an intractable disease characterized by the death of osteocytes that caused by obstructed circulation to a specific area, which ultimately leads to inadequate blood supply [1]. Approximately 70-80\% ONFH patients can eventually result in collapse of necrotic regions of trabecular bone and cartilage degeneration with altered cartilage function, without

\footnotetext{
* Correspondence: yangquanhaop17@21cn.com; spine_surgeon@163.com †Yangquan Hao and Hao Guo contributed equally to this work.

${ }^{1}$ Department of Osteonecrosis and Joint Reconstruction, Honghui Hospital

Xi'an Jiao Tong University Health Science Center, No. 555 Youyi East RoadShaanxi 710054 Xi'an, People's Republic of China

${ }^{2}$ Shaanxi University of Chinese Medicine, Shiji Ave, Xi'an-Xianyang New Ecomic Zone, Shaanxi 712046 Xi'an, People's Republic of China
}

timely treatment [2]. The orientation and distribution of collagen fibrils is crucial for the correct distribution of loads in the bone [3]. Vertically oriented collagen fibrils with large diameter are the characteristics in degenerative articular cartilage, and derangement and breakage of collagen network can been observed in the femoral head with collapse [4]. The quality of life of ONFH patients may be seriously affected with increased economic burdens. Reportedly, it is evaluated that about 100,000 to 200,000 new cases are troubled with osteonecrosis annually in China [5]. Although several factors such as alcohol, steroids and hypercoagulability have been demonstrated to be related to the progression of ONFH [6-9], the exact pathologic mechanism of ONFH is still unclear. Therefore, more 
investigation of the molecular mechanisms of $\mathrm{ONFH}$ is needed.

Recently, several studies have demonstrated the genetic polymorphisms of endothelial nitric oxide synthase (NOS3) and vascular endothelial growth factor (VEGF) contribute to angiogenesis and bone turnover in ONFH patients $[10,11]$, revealing genetic factors may act as crucial role in the development of ONFH. Apolipoprotein $(A P O)$, a major blood plasma protein, mediates the transport of lipid by its interaction with cellular receptors [12], and lipid metabolism disorder is considered as one of the leading causes for ONFH development [13]. APOs are considered as sensitive markers for estimating lipid metabolic disorder in ONFH populations, whose plasma adiponectin levels are significantly lower than that in healthy controls [14]. Adiponectin level is positively correlated with high-density lipoprotein (HDL), but negatively correlated with triglycerides [14]. Reportedly, the apolipoprotein A1 (ApoA1) level is associated with cholesterol homeostasis and lipid metabolism [15]. Similarly, it reveals that the Apo-A1 levels have significant positive correlation with HDL-cholesterol [16]. Notably, the polymorphisms of APOs genes may be associated with ONFH with altered lipid metabolism. ApoA1 rs632153 polymorphism and $A p o B$ rs1042034, rs676210, rs673548 polymorphisms are significantly associated with alcohol-induced ONFH in the Han Chinese population [17]. In addition, $-75 \mathrm{G}>\mathrm{A}$ polymorphism of $A p o A 1$ is associated with susceptibility to osteonecrosis in Chinese population [18]. Moreover, apolipoprotein B $(A p o B)$ gene polymorphism is relevant with the tendon-vessel stagnation syndrome of steroid-induced ONFH [19].

In the recent years, it has proved that genetic susceptibility is closely relevant with ONFH progression, and SNPs and gene mutation are main factors for genetic susceptibility [20, 21]. Several studies have been performed to explore the associations between $A p o A 1$ and $A p o B$ and the susceptibility to ONFH. However, their results are not consistent and the sample sizes are small. Therefore, we applied this meta-analysis to summarize the interactions between polymorphisms of $A p o A 1$ and $A p o B$ and their susceptibility to ONFH.

\section{Methods}

\section{Data resources}

According to Preferred Reporting Items for Systematic Reviews and Meta-Analyses (PRISMA) guidelines, the present meta-analysis was designed and performed [22]. After predetermining the search strategy, related studies were retrieved by a search of several electronic databases including Pubmed, Embase and Cochrane Library, as well as Chinese electronic databases such as Cochrane Library, Wanfang, Chinese Biomedicine Literature Database (CBM) and China National Knowledge Infrastructure (CNKI) to May 2017, with no language restrictions. The search keywords were "osteonecrosis OR Osteonecroses" OR "femoral head necrosis" OR ONFH OR "Osteonecrosis of the Femeral Head" OR "avascular necrosis of femoral head" OR "necrosis of the femoral head" OR "avascular necrosis of bone" OR "Kienbock disease" OR "Aseptic necrosis of bone" and "APO* OR apolipoprotein OR Apoprotein".

\section{Inclusion and exclusion criteria}

The studies were needed to adhere to following inclusion criterion: (1) the studies included two groups, ONFH group as experimental group and non-ONFH group as control group; (2) the studies aimed to explore the relationships between the single nucleotide polymorphism (SNP) of APO genes and ONFH; (3) the studies could provide the data of genotype or allele frequency of $A P O$ genes' polymorphisms in both groups; (4) the article was a case-control study.

In following situations, the study was excluded: (1) the data was incomplete, which could not be applied for statistical analysis; (2) if it was a review, letter or report.

\section{Data extraction and quality assessment}

By using aforementioned methods, two reviewers separately retrieved the databases, as well as extracted the relevant data from included studies. The extracted information included the name of first author, publication time, research region and time, demographic characteristics of cases numbers, age and sex in each group, and the numbers of each genotype of the APO genes' polymorphism in both groups. Then, the quality of per eligible study was evaluated using Newcastle-Ottawa Scale (NOS) recommended by Agency for Healthcare Research and Quality (AHRQ) [23]. A third assessor was required to resolve the disagreements existed on the course of data extraction and literature quality assessment, until a consensus was reached.

\section{Statistical analysis}

At first, in order to detect the genotype stability of $A P O$ genes' polymorphisms in control group, the chi-square test was utilized to perform Hardy-Weinberg equilibrium (HWE) test [24]. Then, the $\mathrm{R} 3.12$ software was used to conduct the present meta-analysis. The odds ratio (OR) and its corresponding 95\% confidence interval (CI) were chosen to calculate the pooled effect size of the dichotomous data [25]. The pooled ORs of per included APO genes' polymorphisms under allele model, additive model, recessive model, and dominant model, were respectively calculated to analyze their relationships with the risk of ONFH.

Additionally, heterogeneity among the included studies was detected using chi-square-based $\mathrm{Q}$ test and $I^{2}$ statistic test [26]. If Q-statistic $\left(P<0.05\right.$ or $\left.I^{2}>50 \%\right)$ was examined, 
indicating there had significant heterogeneity among those studies, and the pooled result needed to measure under the random-effects model. Otherwise $\left(P>0.05\right.$ or $I^{2}<$ $50 \%)$, a fixed-effects model was used [27].

\section{Results}

\section{Eligible studies and their characteristics}

A total of 173 studies were retrieved by using aforementioned strategies: 27 from PubMed, 29 from Embase, 6 from Cochrane Library, 31 from CBM, 29 from CNKI and 51 from Wanfang. After removing 56 duplicates, 117 articles were remained. Then, total 83 articles that did not meet the subject meaning were further excluded by reading the title and abstract of those articles. In addition, 12 articles including 4 letter or editorial and 8 case series or report were also excluded. Afterwards, the remaining 22 articles were full text reviewed, and 16 of them were eliminated due to 4 articles were reviews, 10 with incomplete data and 2 duplicated populations. Therefore, the remaining 6 articles were included in the present study [19, 28-32] (Fig. 1).

A total of 1142 ONFH patients and 920 controls were enrolled in those 6 included studies. The included articles were published during 2007 to 2015, and they were mainly conducted in China and Japan. The NOS scores were ranged from 5 to 7 according to the NOS evaluation system, indicating a high quality. The SNP sites of per included APO genes in present study were $A p o B-3^{\prime}-\mathrm{VNTR}$ (variable number of tandem repeats region $3^{\prime}$ ), $A p o B$ C7623T, $A p o B-G 12619 A, A p o B-E c o R ~ I ~(r s 1042031)$, ApoA1-G75A (rs1799837) and ApoB-Xba I (rs693) (Table 1).
The HWE test indicated that the majority of genotypes distribution of controls at above $A P O$ genes was consistent with HWE $(P>0.05)$, except the ApoA1-G75A (rs1799837) in Yin JM et al' study and Wang XY et al' studies $(P<0.05)$.

\section{Outcomes}

Before quantitative synthesis for per included $A P O$ genes, an appropriate model was chosen to calculate the pooled effect size. There were striking heterogeneity $(P$ $\left.<0.05, I^{2} \geq 50 \%\right)$ among the studies associated with ApoB-G12619A, rs1042031 and rs693 polymorphisms under all genetic models, as well as rs1799837 polymorphism under allele, recessive and dominant models. Therefore, a random-effects model was used to calculate pooled effect size. Meanwhile, except for those noted above, no remarkable heterogeneity between the studies $\left(P>0.05, I^{2}<50 \%\right)$ related to $A p o B$-rs1799837 on other models, and $A p o B-3^{\prime}$-VNTR and $A p o B-C 7623 \mathrm{~T}$ polymorphisms under all genetic models were detected, thus the fix-effects model was used to calculate the pooled OR and 95\% CIs.

\section{Associations between ApoB-3'-VNTR, G12619A, C7623T polymorphisms and ONFH}

Two of six included case-control studies investigated the relationship of $A p o B-3$ '-VNTR polymorphism and ONFH risk [31, 32], and another two studies analyzed the $A p o B$ C7623T and G12619A polymorphisms $[28,29]$. As a result, it showed no significant correlation between the $A p o B-3$ '-VNTR polymorphism and ONFH risk under all the genetic models [allele model (B vs. $S, O R=1.1514$,

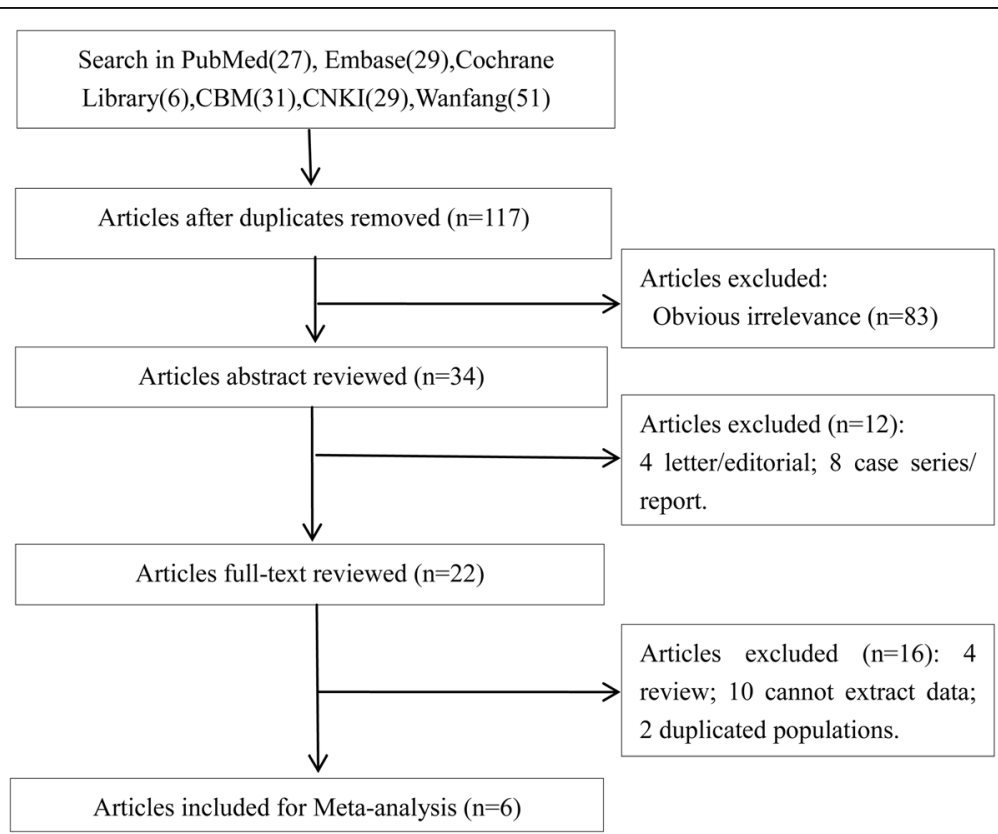

Fig. 1 Flow chart shows the selection process of eligible studies 
Table 1 The characteristics of the included studies

\begin{tabular}{|c|c|c|c|c|c|c|c|c|c|c|c|c|c|c|c|}
\hline \multirow{2}{*}{$\begin{array}{l}\text { Author, Year, } \\
\text { Location }\end{array}$} & \multirow[t]{2}{*}{ Study Year } & \multirow[t]{2}{*}{ NOS } & \multirow{2}{*}{$\begin{array}{l}\text { Age } \\
\text { ONFH/Control }\end{array}$} & \multirow{2}{*}{$\begin{array}{l}\text { Gender(Male) } \\
\text { ONFH/Control }\end{array}$} & \multirow[t]{2}{*}{ SNPs } & \multicolumn{4}{|c|}{ ONFH } & \multicolumn{4}{|c|}{ Control } & \multicolumn{2}{|l|}{ HWE } \\
\hline & & & & & & $\mathrm{N}$ & WH & HT & $\mathrm{MH}$ & $\mathrm{N}$ & $\mathrm{WH}$ & $\mathrm{HT}$ & $\mathrm{MH}$ & $x^{2^{*}}$ & $P$ \\
\hline \multirow[t]{4}{*}{$\begin{array}{l}\text { Yin JM, [32] } \\
\text { 2014, China }\end{array}$} & \multirow[t]{4}{*}{ 2001.11-2013.9 } & \multirow[t]{4}{*}{7} & \multirow[t]{4}{*}{$\begin{array}{l}44.6 \pm 11.3 / \\
44.7 \pm 11.7\end{array}$} & \multirow[t]{4}{*}{$326 / 278$} & $\begin{array}{l}\text { ApoA1- } \\
\text { G75A(rs1799837) }\end{array}$ & 429 & 215 & 73 & 141 & 368 & 170 & 114 & 84 & 43.758 & $<0.001$ \\
\hline & & & & & $\begin{array}{l}\text { ApoB-EcoR I } \\
\text { (rs1042031) }\end{array}$ & 429 & 391 & 38 & 0 & 368 & 324 & 44 & 0 & 1.488 & 0.2226 \\
\hline & & & & & $\begin{array}{l}\text { ApoB-Xba } \\
\text { I(rs693) }\end{array}$ & 429 & 394 & 35 & 0 & 368 & 327 & 41 & 0 & 1.281 & 0.2578 \\
\hline & & & & & ApoB-3'-VNTR & 429 & 336 & 93 & 0 & 368 & 299 & 69 & 0 & 3.938 & 0.0583 \\
\hline \multirow{3}{*}{$\begin{array}{l}\text { Hirata T, [29] } \\
\text { 2007, Japan }\end{array}$} & \multirow[t]{3}{*}{ 1983-2004 } & \multirow[t]{3}{*}{7} & \multirow{3}{*}{$\begin{array}{c}40.8(20-64) / \\
36.1(9-63)\end{array}$} & \multirow[t]{3}{*}{ 22/91 } & ApoB-C7623T & 33 & 27 & 6 & 0 & 122 & 115 & 6 & 1 & 2.755 & 0.0969 \\
\hline & & & & & ApoB-G12619A & 34 & 33 & 1 & 0 & 123 & 112 & 11 & 0 & 0.2690 & 0.6037 \\
\hline & & & & & $\begin{array}{l}\text { ApoA1- } \\
\text { G75A(rs1799837) }\end{array}$ & 33 & 22 & 11 & & 120 & 86 & 34 & & - & - \\
\hline \multirow[t]{4}{*}{$\begin{array}{l}\text { Wang XY, [31] } \\
\text { 2008, China }\end{array}$} & \multirow[t]{4}{*}{ 2003.10-2005.9 } & \multirow[t]{4}{*}{5} & \multirow[t]{4}{*}{$\begin{array}{l}41.6 \pm 10.3 / \\
40.7 \pm 14.7\end{array}$} & \multirow[t]{4}{*}{$98 / 48$} & $\begin{array}{l}\text { ApoA1- } \\
\text { G75A(rs1799837) }\end{array}$ & 143 & 70 & 20 & 53 & 92 & 45 & 28 & 19 & 10.447 & 0.0012 \\
\hline & & & & & $\begin{array}{l}\text { ApoB-EcoR } \\
\text { I(rs1042031) }\end{array}$ & 143 & 125 & 18 & 0 & 92 & 82 & 10 & 0 & 0.304 & 0.5815 \\
\hline & & & & & $\begin{array}{l}\text { ApoB-Xba } \\
\text { I(rs693) }\end{array}$ & 143 & 126 & 17 & 0 & 92 & 87 & 5 & 0 & 0.072 & 0.7888 \\
\hline & & & & & ApoB-3'-VNTR & 142 & 109 & 33 & 0 & 92 & 73 & 18 & 1 & 0.009 & 0.9247 \\
\hline \multirow[t]{2}{*}{$\begin{array}{l}\text { Zeng P, [19] } \\
\text { 2014, China }\end{array}$} & \multirow[t]{2}{*}{ 2010.1-2013.12 } & \multirow[t]{2}{*}{5} & \multirow[t]{2}{*}{$\begin{array}{l}39.85 \pm 10.07 / \\
41.04 \pm 13.61\end{array}$} & \multirow[t]{2}{*}{$53 / 38$} & $\begin{array}{l}\text { ApoB-EcoR } \\
\text { I(rs1042031) }\end{array}$ & 108 & 95 & 13 & 0 & 98 & 96 & 2 & 0 & 0.010 & 0.9187 \\
\hline & & & & & $\begin{array}{l}\text { ApoB-Xba } \\
\text { I(rs693) }\end{array}$ & 108 & 89 & 19 & 0 & 98 & 92 & 6 & 0 & 0.098 & 0.7546 \\
\hline \multirow[t]{3}{*}{$\begin{array}{l}\text { Wei XD, [30] } \\
\text { 2015, China }\end{array}$} & \multirow[t]{3}{*}{$2011.1-2012.12$} & 6 & $39 \pm 10 / 41 \pm 14$ & $28 / 14$ & $\begin{array}{l}\text { ApoA1- } \\
\text { G75A(rs1799837) }\end{array}$ & 45 & 32 & 13 & 0 & 30 & 28 & 2 & 0 & 0.036 & 0.8502 \\
\hline & & & & & $\begin{array}{l}\text { ApoB-Xba } \\
\text { I(rs693) }\end{array}$ & 45 & 41 & 4 & 0 & 30 & 26 & 4 & 0 & 0.153 & 0.6956 \\
\hline & & & & & $\begin{array}{l}\text { ApoB-EcoR } \\
\text { I(rs1042031) }\end{array}$ & 45 & 31 & 14 & 0 & 30 & 27 & 3 & 0 & 0.083 & 0.7731 \\
\hline Wei BF, [28] & 2007.1-2009.12 & 5 & $35.17 \pm 11.73 /$ & $27 / 30$ & ApoB-C7623T & 63 & 57 & 6 & 0 & 71 & 71 & 0 & 0 & - & 1.000 \\
\hline 2011, Cnina & & & & & ApoB-G12619A & 63 & 56 & 7 & 0 & 71 & 69 & 2 & 0 & 0.014 & 0.9042 \\
\hline
\end{tabular}

SNP Single Nucleotide Polymorphism, $\mathrm{X}^{2^{*}}$ likelihood-ratio $X^{2}, W H$ Wild homozygote, $H T$ Heterozygote, $M H$ mutational homozygote, NOS Newcastle-Ottawa Scale, $N$ The total number of including, ONFH Osteonecrosis of the Femeral Head, HWE Hardy-Weinberg equilibrium tests

95\% CI: 0.8643-1.5339); additive model (BB vs. SS, OR = 0.2237, 95\% CI: 0.0090-5.5676); additive model (BS vs. SS, $\mathrm{OR}=1.2058,95 \% \mathrm{CI}: 0.8875-1.6383)$; recessive model (BB vs. $\mathrm{SS}+\mathrm{BS}, \mathrm{OR}=0.2140,95 \% \mathrm{CI}$ : 0.0096-5.3108); dominant model (BB + BS vs. SS, OR $=1.1910$, 95\% CI: 0.87731.6167; Fig. 2)].

Similarly, it also showed lack of significant relationship of ApoB-G12619A polymorphism with susceptibility to ONFH under three genetic models [allele model (A vs. G, OR $=1.2499$, 95\% CI: 0.1005-15.5444); additive model (AG vs. GG, OR = 1.2557, 95\% CI: 0.0933-16.8940); dominant model (AA + AG vs. GG, OR $=1.2557,95 \% \mathrm{CI}$ : 0.0933-16.8940; Fig. 3)].

Notably, the increased $A p o B-C 7623 \mathrm{~T}$ polymorphism frequencies was observed in ONFH group than in control group under three genetic models [allele model ( $\mathrm{T}$ vs. C, $\mathrm{OR}=4.5149$, 95\% CI: 1.6968-12.0134); additive model (TC vs. $\mathrm{CC}$, $\mathrm{OR}=6.2515$, 95\% CI: 2.0939-18.6640); and dominant model (TT + TC vs. CC, OR $=5.4998,95 \% \mathrm{CI}$ : 1.9246-15.7163; Fig. 4)].

\section{Associations between ApoB-rs1042031, rs693 polymorphisms and ONFH}

Four of the six studies analyzed the rs1042031 and rs693 polymorphisms in $A p o B$ gene [19, 30-32]. The outcomes showed that the genetic mutation frequencies of ApoB-rs1042031 polymorphism in ONFH patients were not significantly increased than in normal controls under three genetic models [allele model (A vs. G, OR $=1.6863$, 95\% CI: 0.6928-4.1047); additive model (AG vs. GG, OR = 1.7809, 95\% CI: 0.6891-4.6025); dominant model (AA + AG vs. GG, OR = 1.7809, 95\% CI: $0.6891-$ 4.6025; Fig. 5)]. In addition, there was no significant difference in rs693 polymorphism between ONFH group and normal group under three genetic models [allele model ( $\mathrm{T}$ vs. $\mathrm{C}, \mathrm{OR}=1.3371,95 \% \mathrm{CI}$ : $0.5852-$ 


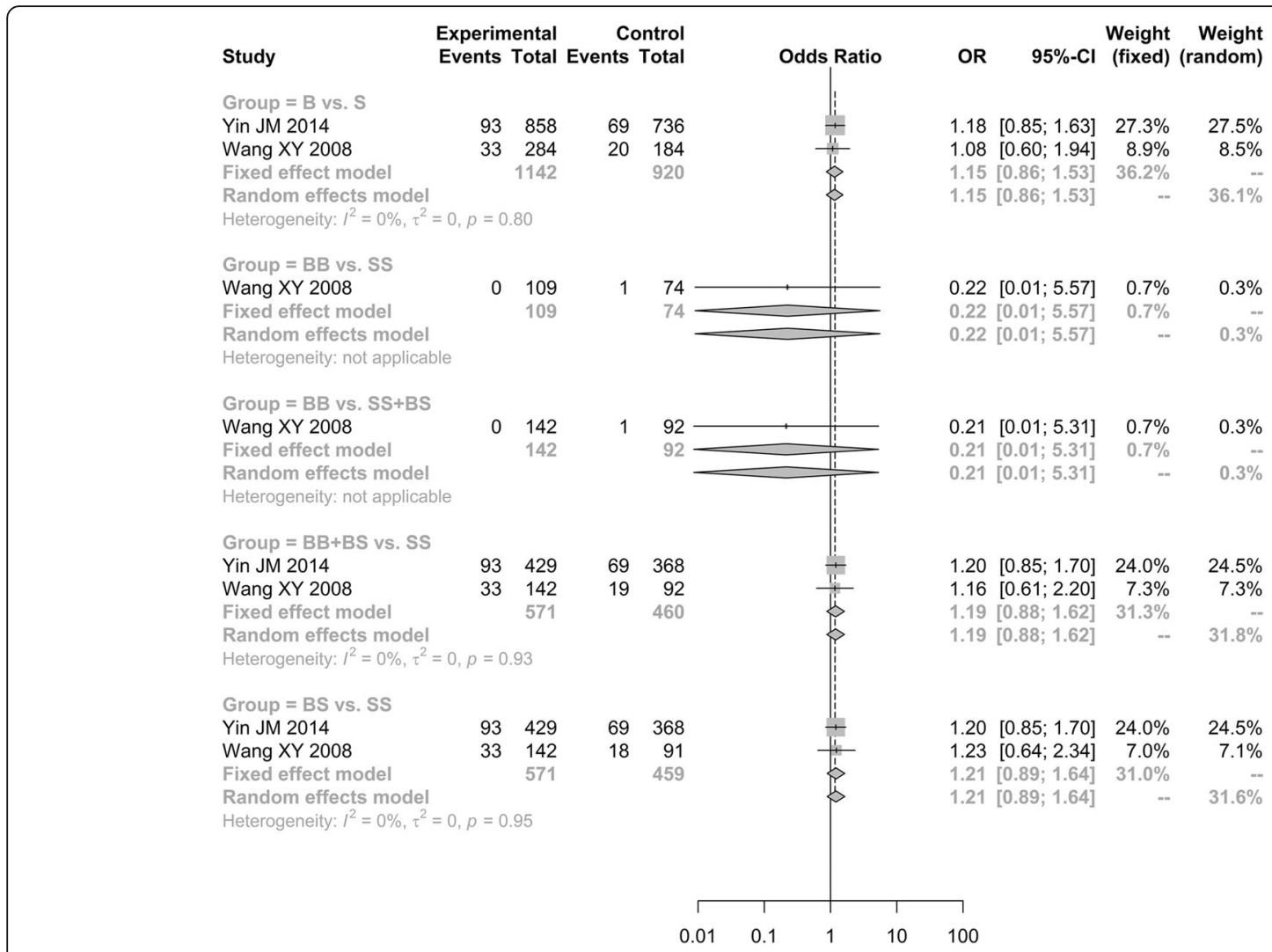

Fig. 2 Forest plot of the quantitative synthesis of ApoB-3'-VNTR in ONFH and non-ONFH groups. ONFH: Osteonecrosis of the femoral head. ApoB: apolipoprotein B

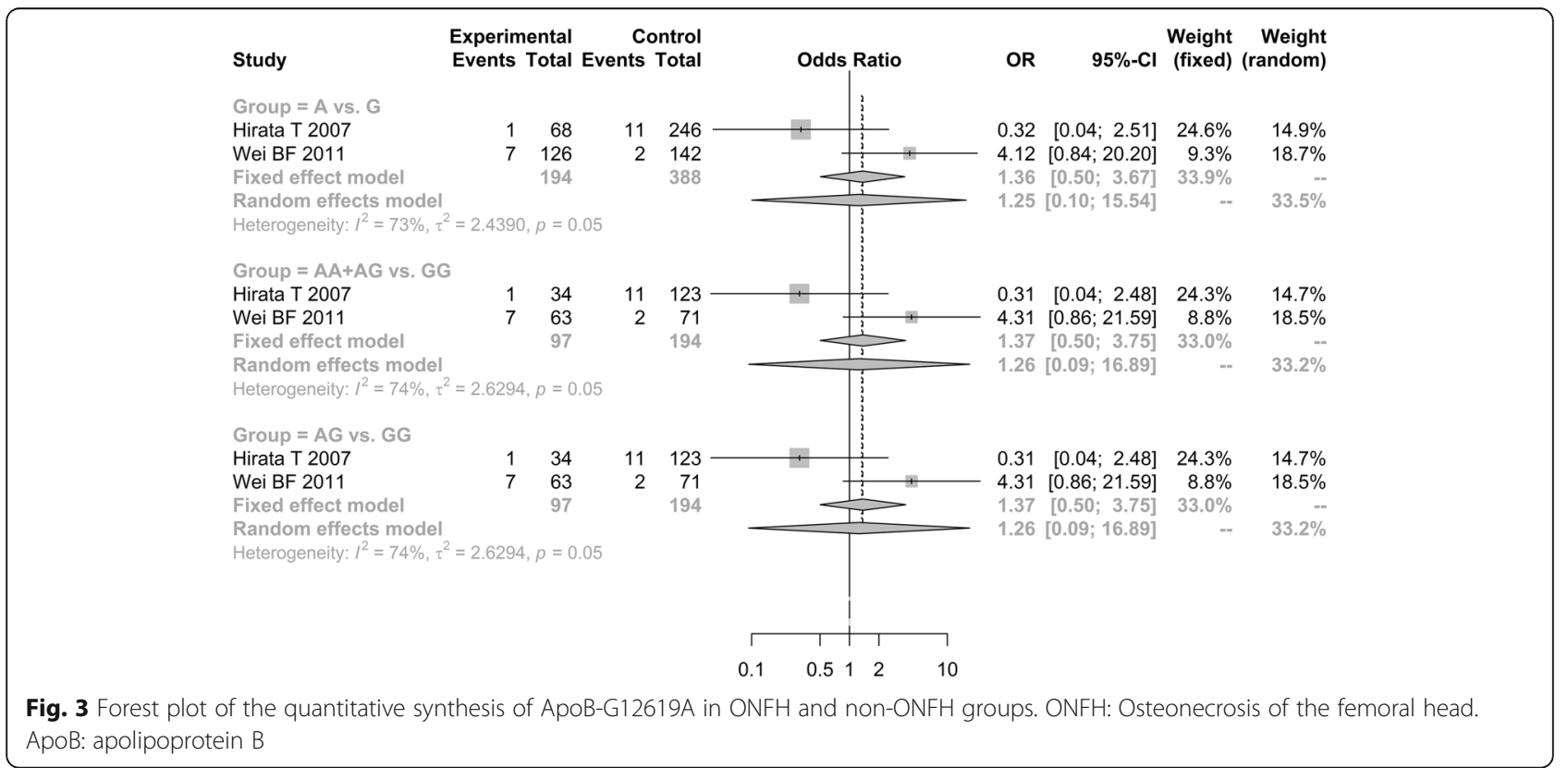




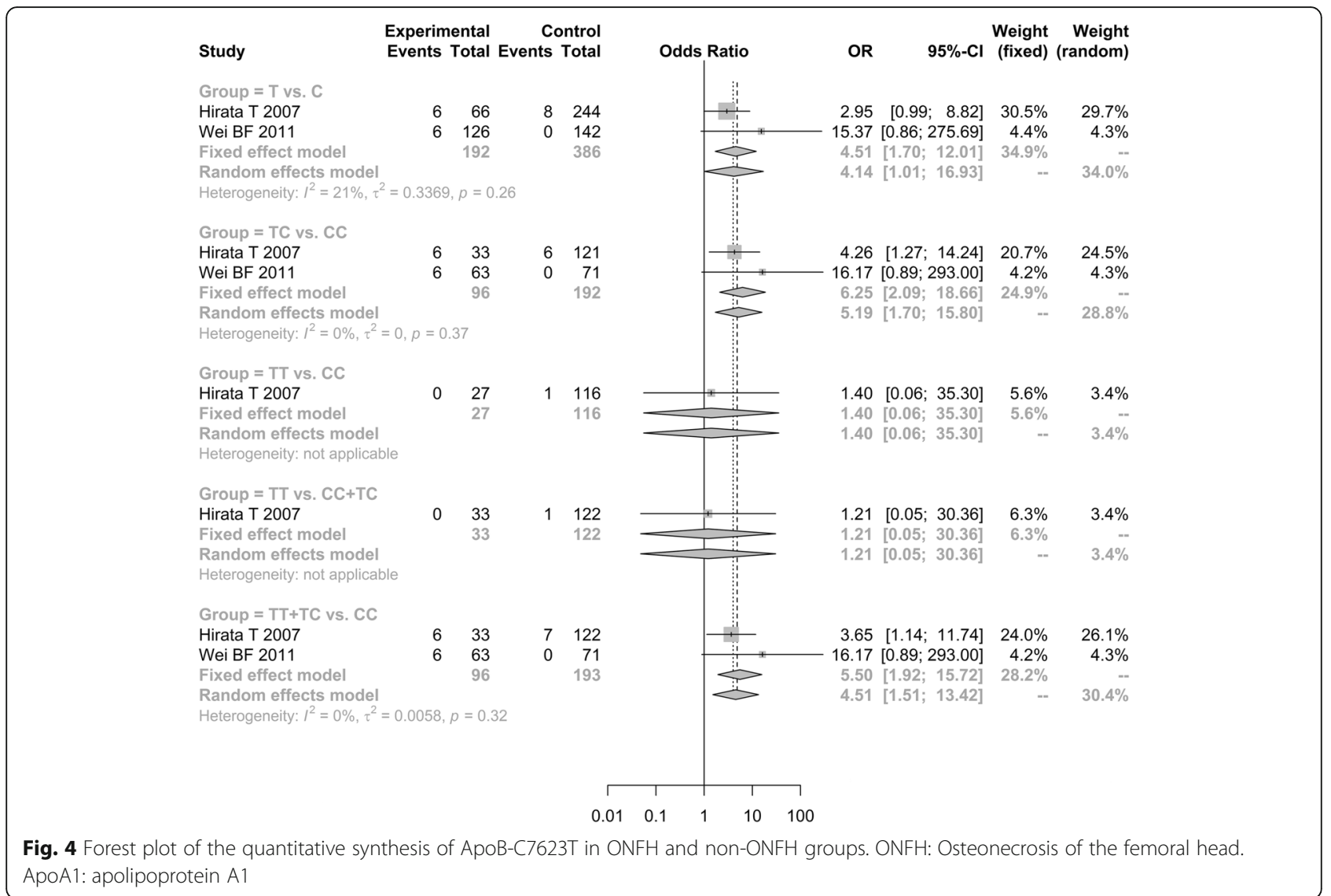

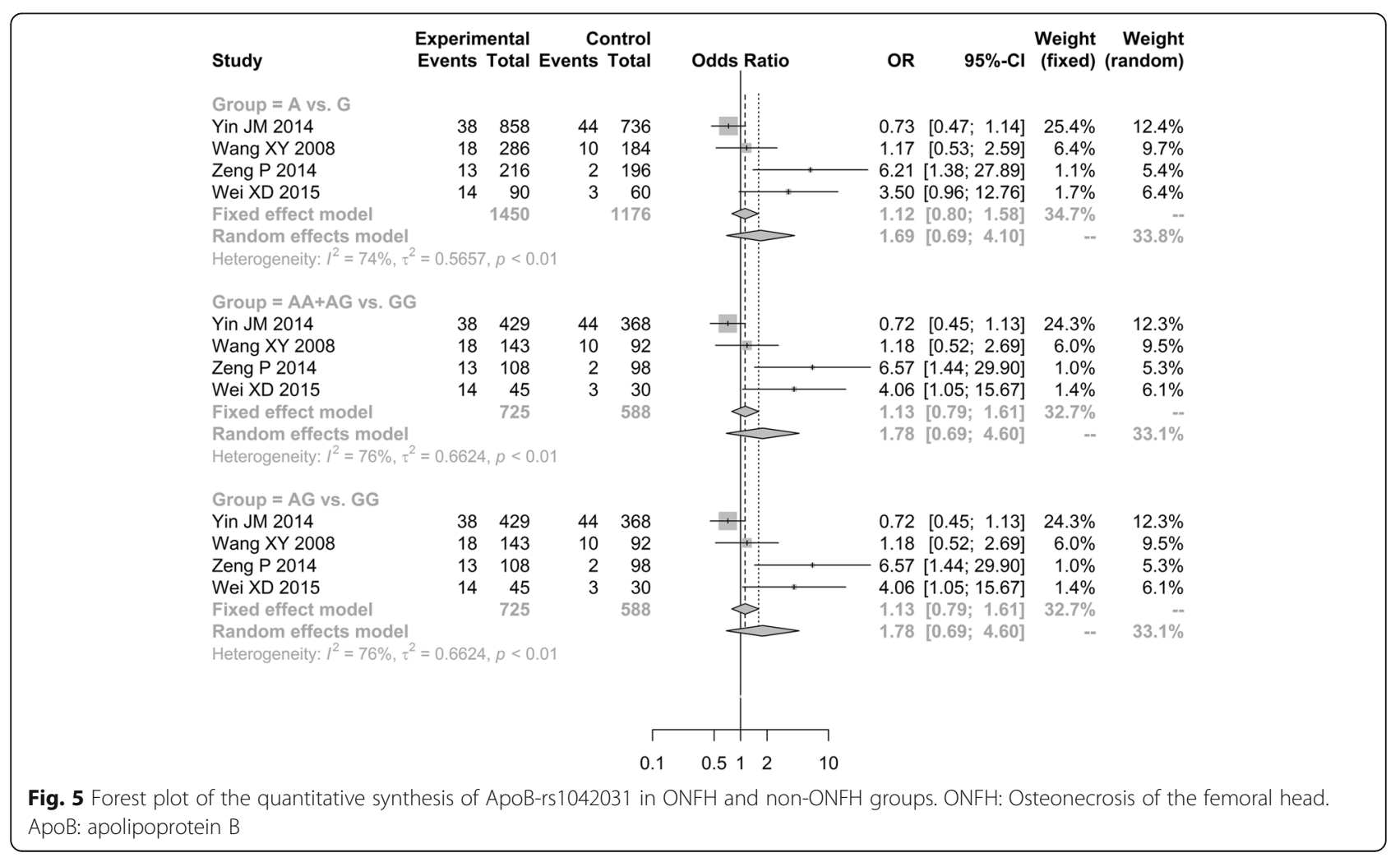


3.0553); additive model ( $\mathrm{TC}$ vs. $\mathrm{CC}, \mathrm{OR}=1.3630,95 \%$ CI: 0.5695-3.2621); dominant model (TT + TC vs. CC, $\mathrm{OR}=1.3630,95 \%$ CI: 0.5695-3.2621; Fig. 6)].

\section{Association between ApoA1-rs1799837 polymorphism and ONFH}

A total of four studies assessed the association of ApoA1-rs1799837 polymorphism with the occurrence of ONFH [29-32]. The outcomes showed that the ApoA1-rs1799837 was associated with the susceptibility to ONFH under additive model (AA vs. GG, OR $=1.4175$, 95\% CI: 1.0522-1.9096) and recessive model (AA vs. GG + AG, OR $=1.7727,95 \%$ CI: 1.3399-2.3452). However, it showed that the ApoA1-rs1799837 polymorphism frequencies in ONFH patients were not significantly increased than in controls under three genetic models [allele model (A vs. G, $\mathrm{OR}=1.3317,95 \% \mathrm{CI}: 0.9275-1.9121$ ); additive model (AG vs. GG, OR = 0.7821, 95\% CI: 0.3153-1.9399); and dominant model (AA+AG vs. GG, OR $=1.096,95 \%$ CI: 0.7068-1.6998; Fig. 7)].

\section{Discussion}

In the present study, the relationships of $A p o B-3^{\prime}$-VNTR, C7623T, G12619A, rs1042031, rs693 polymorphisms and ApoA1 rs1799837 polymorphism with susceptibility to $\mathrm{ONFH}$ were investigated. It showed that $A p o B-C 7623 \mathrm{~T}$ polymorphism in allele model ( $\mathrm{T}$ vs. $\mathrm{C}$ ), additive model (TC vs. CC) and dominant model (TT + TC vs. CC) was closely associated with susceptibility to ONFH. In addition, ApoA1-rs1799837 polymorphism was related to the susceptibility of ONFH in additive model (AA vs. GG) and recessive model (AA vs. AG + GG). However, the ApoB-3'-VNTR, G12619A, rs1042031 and rs693 polymorphisms were not significantly associated with susceptibility to ONFH.

ApoB and ApoA1 are the major structural and functional protein constituents of the HDL and triglyceride-rich lipoproteins [33]. The apoB plasma level may reflect the concentration of LDL cholesterol [34], while apoA1 protein level is correlated with increased HDL cholesterol [35]. it has been suggested that the increased ratio of low density lipoprotein to high density lipoprotein (LDL/HDL ratio) can result in overloaded fatty emboli, which play an crucial role in the onset of $\mathrm{ON}[36,37]$. Additionally, it is considered that the elevated level of apoB/apoA1 ratio acts as a potential risk for ON [38]. Those abnormal lipid metabolisms may increase the risk of ONFH via impacting bone repair and reconstruction $[39,40]$.

In the present study, the frequencies of $\mathrm{T}$ allele and TC genotype at $A p o B-C 7623 \mathrm{~T}$ locus in ONFH patients were significantly higher than those in non-ONFH patients or controls. In addition, the additive model (AA vs. GG) and recessive model (AA vs. AG + GG) in ApoA1-rs1799837 were also significantly associated with the increased risk of ONFH. Similarly, two studies have found that the TT or TC genotypes of $A p o B-C 7623 \mathrm{~T}$ and A allele of ApoA1(rs1799837) are significantly correlative with higher risks of ONFH $[28,29]$. Additionally, Yin et al. have

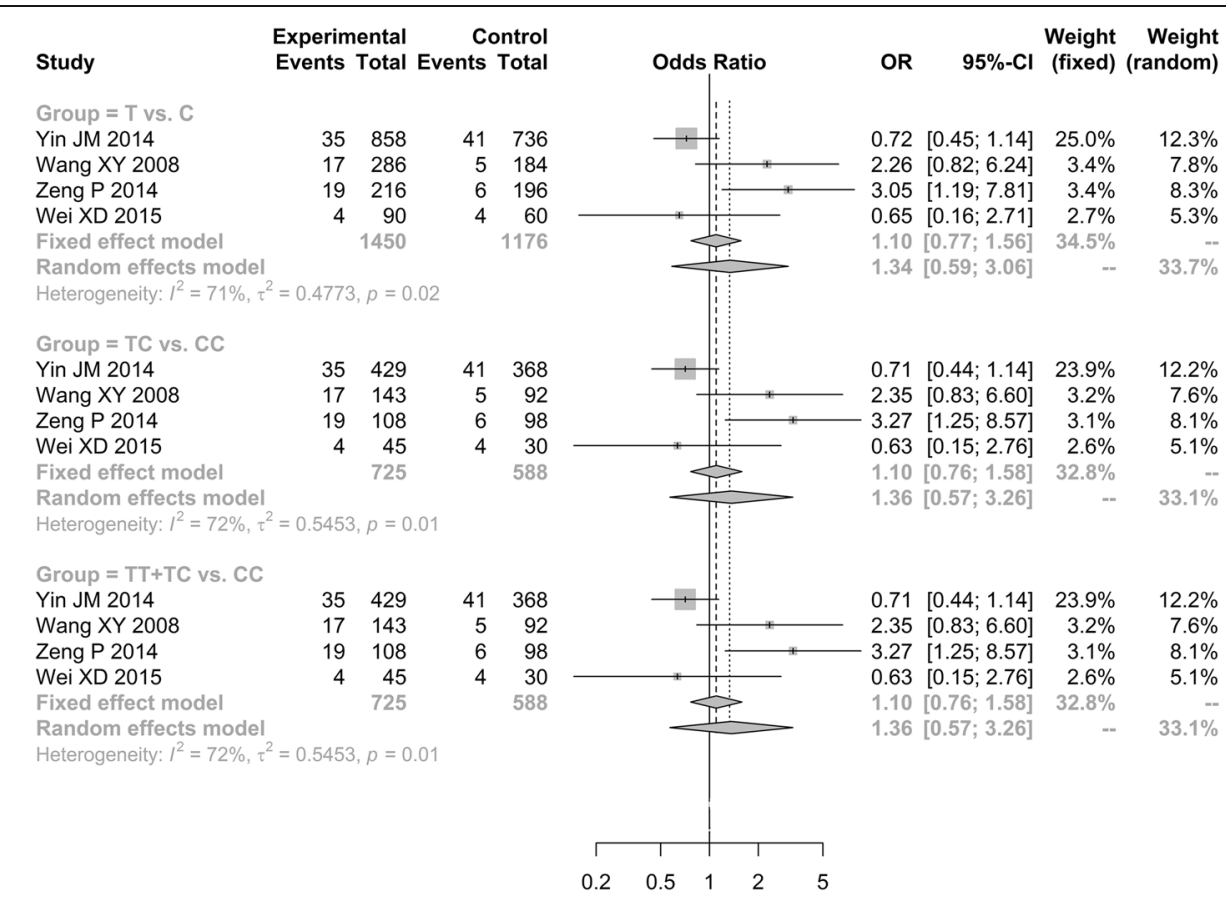

Fig. 6 Forest plot of the quantitative synthesis of ApoB-rs693 in ONFH and non-ONFH groups. Squares denote the study-specific outcome estimates, and the size of the square represents the study-specific weight. ONFH: Osteonecrosis of the femoral head. ApoB: apolipoprotein B 


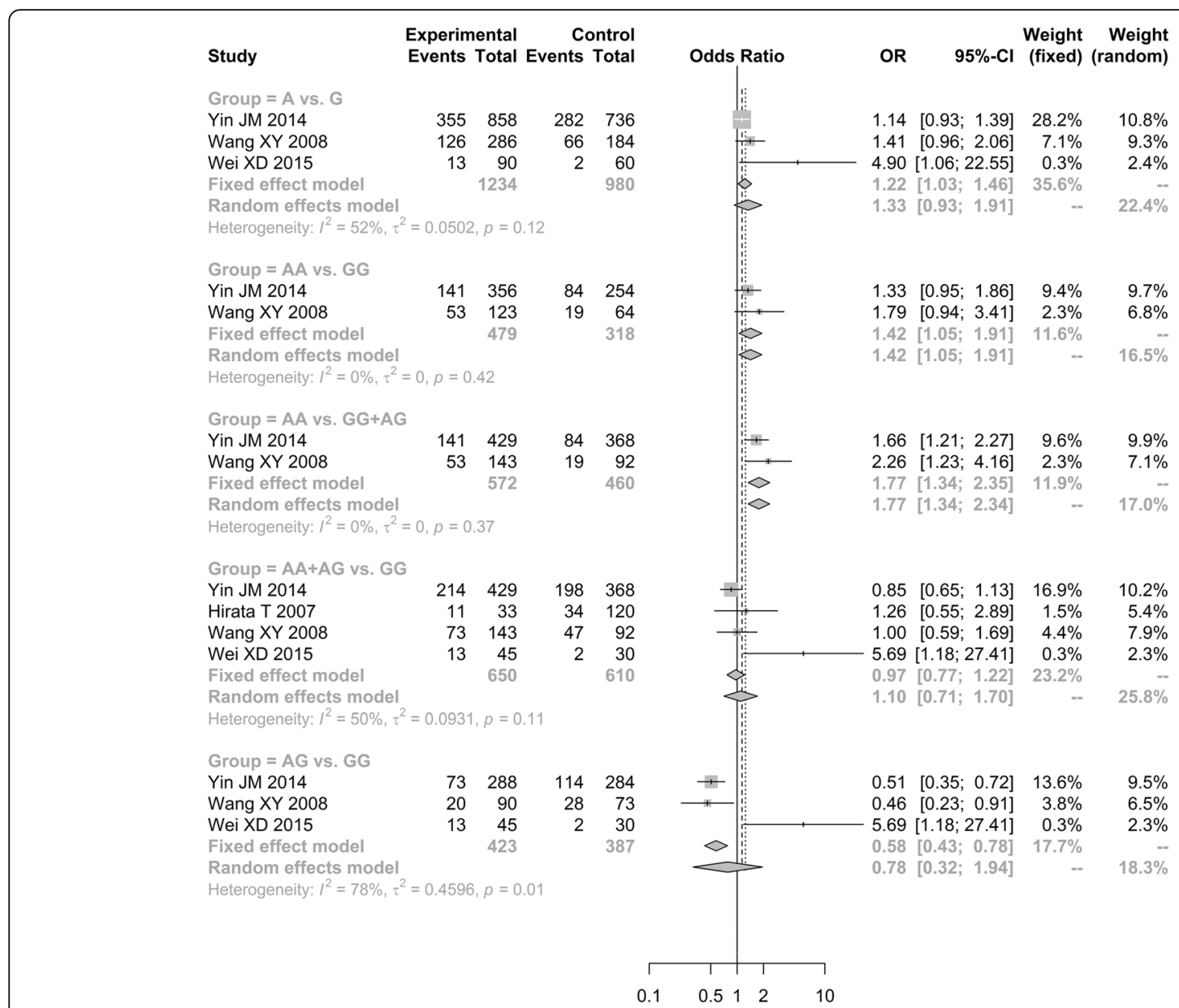

Fig. 7 Forest plot of the quantitative synthesis of Apo A1-rs1799837 in ONFH and non-ONFH groups. ONFH: Osteonecrosis of the femoral head. ApoB: apolipoprotein B

demonstrated that ApoA1-75 bp G > A (rs1799837) is associated with the levels of total cholesterol and HDL in the serum lipid levels [41, 42]. In addition, Hirata et al. have found that there is no significant relationship of the GA or AA genotypes of ApoA1-rs1799837 with susceptibility to ONFH in Japanese population [29]. Conversely, the GA or AA genotypes frequency of ApoA1-rs1799837 are remarkably higher in the ONFH patients than in normal controls from Chinese population [30]. Thus, the racial differences might be the cause of the difference.

Moreover, although it revealed the four $A p o B$ rs1042031, rs693, 3'-VNTR and G12619A polymorphism under all genetic models were not strongly linked to the high risk of ONFH in our work, the pooled OR of those four $A p o B$ polymorphisms were higher in ONFH group. The AG and AA genotypes frequency of $A p o B$-rs1042031 are higher in the dyslipidemia group [43]. Meanwhile, the rs1042031 and rs693 polymorphisms of $A p o B$ are the lipid profile genetic related in the Kuwait population [44].

In spite of some important findings are revealed in the present study, several limitations are still existed. Firstly, there was significant heterogeneity between the included studies, which might be caused by the different research regions. Meanwhile, the gender and age might also account for the high heterogeneity. Phillips et al. have suggested that gender regulates the association between $A p o B$ and $A p o A 1$ gene polymorphisms and metabolic syndrome risk [33]. Secondly, covariate adjustment and subgroup analysis were not performed, and it might potentially influence the results of the present study. Thirdly, the findings might only be appropriate for the China and Japanese populations. Fourthly, the genotype frequency of Apo AI-G75A (rs1799837) for control group Yin JM et al' study and Wang XY et al' studies were not consistent with HWE, indicating that the selected samples in control group might be unable to represent the population in the area. Fifthly, publication bias wasn't evaluated since the number of included studies $<10$ was limited to conduct Egger's test.

\section{Conclusion}

To summarize, the present study suggested that the $\mathrm{T}$ allele and TC genotype of ApoB-C7623T, ApoA1-rs1799837 
under allele, additive and dominant models might contribute to increase the risk of ONFH in both China and Japanese populations. In addition, it revealed that the four $A p o B$ rs1042031, rs693, 3'-VNTR and G12619A polymorphisms under all genetic models were not strongly associated with the increased risk of ONFH. However, larger scale case-control studies with more patients and controls participants should be included to further assess the interaction of above $A p o B$ and $A p o A 1$ polymorphisms with ONFH susceptibility.

\begin{abstract}
Abbreviations
AHRQ: Agency for Healthcare Research and Quality; APO: Apolipoprotein; ApoA1: Apolipoprotein A1; ApoB: Apolipoprotein B; CBM: Chinese Biomedicine Literature Database; Cl: Confidence interval; HWE: HardyWeinberg equilibrium; NOS: Newcastle-Ottawa Scale; NOS3: Nitric oxide synthase; ONFH: Osteonecrosis of the femoral head; OR: Odds ratio; PRISMA: Preferred Reporting Items for Systematic Reviews and MetaAnalyses; SNP: Single nucleotide polymorphism; VEGF: Vascular endothelial growth factor
\end{abstract}

\section{Availability of data and materials}

The datasets used and analyzed in the current study are available from the corresponding author in response to reasonable requests.

\section{Authors' contributions}

YQH, HG and ZX conceived and designed the project; $\mathrm{HDQ}, \mathrm{YGW}$ and $\mathrm{CL}$ performed the statistical analysis; $J$ and PWY wrote the manuscript. All authors read and approved the final manuscript.

\section{Ethics approval and consent to participate}

Not applicable.

\section{Consent for publication}

Not applicable

\section{Competing interests}

The authors declare that they have no competing interests.

\section{Publisher's Note}

Springer Nature remains neutral with regard to jurisdictional claims in published maps and institutional affiliations.

Received: 18 January 2018 Accepted: 16 July 2018

Published online: 17 August 2018

\section{References}

1. Malizos KN, Karantanas AH, Varitimidis SE, Dailiana ZH, Bargiotas K, Maris T. Osteonecrosis of the femoral head: etiology, imaging and treatment. Eur J Radiol. 2007:63:16-28.

2. Magnussen RA, Guilak F, Vail TP. Cartilage degeneration in post-collapse cases of osteonecrosis of the human femoral head: altered mechanical properties in tension, compression, and shear. J Orthopaedic Res. 2005;23: 576-83.

3. Bordoni B, Marelli F, Morabito B, Sacconi B. The indeterminable resilience of the fascial system. J Integr Med. 2017:15:337-43.

4. Maniwa S, Sakai Y, Tadenuma T, Uchio Y, Kadowaki M. Microstructural observation of collagen fibrils in the articular cartilage reveals a structural divergence depending on its local mechanical environment in human femoral head. Osteoarthritis Cartil. 2014;22:S353-S.

5. Chen J, Liu W, Cao Y, Zhang X, Guo Y, Zhu Y, et al. MMP-3andMMP-8singlenucleotide polymorphisms are related to alcohol-induced osteonecrosis of the femoral head in Chinese males. Oncotarget. 2017;8:25177-88.

6. Sakai T, Sugano N, Ohzono K, Matsui M, Hiroshima K, Ochi T. MRI evaluation of steroid- or alcohol-related osteonecrosis of the femoral condyle. Acta Orthop Scand. 2009;69:598-602.

7. Fukushima W, Yamamoto T, Takahashi S, Sakaguchi M, Kubo T, Iwamoto Y, et al. The effect of alcohol intake and the use of oral corticosteroids on the risk of idiopathic osteonecrosis of the femoral head: a case-control study in Japan. Bone Joint J. 2013;95-B:320-5.

8. Lykissas MG, Gelalis ID, Kostas-Agnantis IP, Georgios V, Korompilias AV. The role of hypercoagulability in the development of osteonecrosis of the femoral head. Orthop Rev. 2012;4:73-8.

9. Gagala J, Buraczynska M, Mazurkiewicz T, Ksiazek A. Prevalence of genetic risk factors related with thrombophilia and hypofibrinolysis in patients with osteonecrosis of the femoral head in Poland. BMC Musculoskelet Disord. 2013;14:1-7.

10. Kim HS, Bae SC, Kim TH, Kim SY. Endothelial nitric oxide synthase gene polymorphisms and the risk of osteonecrosis of the femoral head in systemic lupus erythematosus. Int Orthop. 2013;37:2289-96.

11. Hong GJ, Lin N, Chen LL, Chen XB, He W. Association between vascular endothelial growth factor gene polymorphisms and the risk of osteonecrosis of the femoral head: systematic review. Biomed Rep. 2016;4:92-6.

12. Marcel YL, Mcpherson R, Hogue M, Czarnecka H, Zawadzki Z, Weech PK, et al. Distribution and concentration of cholesteryl ester transfer protein in plasma of normolipemic subjects. J Clin Investig. 1990;85:10-7.

13. Fujita M. THE SEARCH FOR CAUSES OF OSTEONECROSIS OF THE FEMORAL HEAD:-focusing on Examinations of Lipid Metabolism and HLA-. J Showa Univ Soc. 2006:66:269-81.

14. Shuai B, Shen L, Yang YP, Xie J, Shou ZX, Wei B. Low plasma adiponectin as a potential biomarker for osteonecrosis of the femoral head. J Rheumatol. 2010;37:2151

15. Karathanasis SK. Regulation of the apolipoprotein Al gene by ARP-1, a novel member of the steroid receptor superfamily. Science. 1991;251:561-5.

16. Hajmohammadi Z, Heydari M, Nimrouzi M, Faridi P, Zibaeenezhad MJ, Omrani GR, et al. Rhus coriaria L. increases serum apolipoprotein-A1 and high-density lipoprotein cholesterol levels: a double-blind placebocontrolled randomized clinical trial. J Integr Med. 2018;16:45-50.

17. Wang Y, Cao Y, Li Y, Guo Y, Wang Q, Yang M, et al. Genetic association of the $A p o B$ and $A p o A 1$ gene polymorphisms with the risk for alcohol-induced osteonecrosis of femoral head. Int J Clin Exp Pathol. 2014;8:11332-9.

18. Yin JM, Zhao L, Zhao SC, Guo YJ, Liu ZT. Relationship between the Apolipoprotein Al, B gene polymorphism and the risk of non-traumatic osteonecrosis. Lipids Health Dis. 2013:13:1-5.

19. Zeng $P$, Liang JC, Wei XD, Wei BF. Relationship between apolipoprotein $B$ gene polymorphism and tendon-vessel stagnation syndrome of steroid induced osteonecrosis of the femoral head. Shandong Med J. 2014;54:1-3.

20. He W, Li K. Genetic susceptibility of corticosteroid-induced osteonecrosis of femoral head. Chin Bone Joint Surg. 2009;2:284-9.

21. Björkman A, Svensson PJ, Hillarp A, Burtscher IM, Rünow A, Benoni G. Factor $\checkmark$ Leiden and prothrombin gene mutation: risk factors for osteonecrosis of the femoral head in adults. Clin Orthop Relat Res. 2004;425:168-72.

22. Moher D, Liberati A, Tetzlaff J, Altman DG. Preferred reporting items for systematic reviews and meta-analyses: the PRISMA statement. Ann Intern Med. 2009:151:264-9.

23. Wells GA, Shea BJ, O'Connell D, Peterson J, Welch V, Losos M, et al. The Newcastle-Ottawa Scale (NOS) for Assessing the Quality of NonRandomized Studies in Meta-Analysis. 2000.

24. Schaid DJ, Jacobsen SJ. Blased tests of association: comparisons of allele frequencies when departing from hardy-Weinberg proportions. Am J Epidemiol. 1999:149:706-11.

25. Liu T, Xu QE, Zhang CH, Zhang P. Occupational exposure to methylene chloride and risk of cancer: a meta-analysis. Cancer Causes Control. 2013:24:2037-49.

26. Lau J, loannidis JP, Schmid CH. Quantitative synthesis in systematic reviews. Ann Intern Med. 1997;127:820-6.

27. Feng RN, Zhao C, Sun CH, Li Y. Meta-analysis of TNF $308 \mathrm{G} /$ a polymorphism and type 2 diabetes mellitus. PLoS One. 2011;6:e18480.

28. Wei BF. Relationship between gene polymorphisms and hereditary susceptibility of steroid-induced femoral head osteonecrosis in Linyi city of Shandong Province. J Clin Rehabil Tissue Eng Res. 2011;15:7403-6.

29. Hirata T, Fujioka M, Takahashi KA, Arai Y, Asano T, Ishida M, et al. ApoB C7623T polymorphism predicts risk for steroid-induced osteonecrosis of the femoral head after renal transplantation. J Orthop Sci. 2007;12:199-206.

30. Wei XD, Liang JC, Zeng P, Qin G, Wei BF. The correlation between apolipoprotein gene polymorphisms and steroid-induced osteonecrosis of the femoral head. Shandong Med J. 2015:36:1364-8.

31. Wang X, Niu X, Chen W, Lin N, Song J, Chen B, et al. Effects of apolipoprotein $A 1$ and $B$ gene polymorphism on avascular necrosis of the femoral head in Chinese population. Zhongguo Gu Shang. 2008;21:99-102. 
32. Yin J-M, Liu Z, Zhao S-C, Guo Y-J, Liu Z-T. Relationship between the Apolipoprotein Al, B gene polymorphism and the risk of non-traumatic osteonecrosis. Lipids Health Dis. 2014;13:149.

33. Phillips CM, Goumidi L, Bertrais S, Field MR, Mcmanus R, Hercberg S, et al. Gene-nutrient interactions and gender may modulate the association between $A p o A 1$ and $A p o B$ gene polymorphisms and metabolic syndrome risk. Atherosclerosis. 2011;214:408-14.

34. Pischon T, Girman CJ, Sacks FM, Rifai N, Stampfer MJ, Rimm EB. Non-highdensity lipoprotein cholesterol and apolipoprotein B in the prediction of coronary heart disease in men. Circulation. 2005;1 12:3375-83.

35. Pulkkinen A, Viitanen L, Kareinen A, Lehto S, Laakso M. MSPI polymorphism at $+83 \mathrm{bp}$ in intron 1 of the human apolipoprotein A1 gene is associated with elevated levels of high density lipoprotein cholesterol and apolipoprotein A1 in nondiabetic subjects but not in type 2 diabetic patients with coronary heart dis. Diabetes Care. 2000:151:179.

36. Miyanishi K, Yamamoto T, Irisa T, Yamashita A, Jingushi S, Noguchi Y, et al. A high low-density lipoprotein cholesterol to high-density lipoprotein cholesterol ratio as a potential risk factor for corticosteroid-induced osteonecrosis in rabbits. Rheumatology. 2001;40:196-201.

37. Jr Jones JP. Fat embolism, intravascular coagulation, and osteonecrosis. Clin Orthop Relat Res 1993;292:294-308.

38. Miyanishi K, Yamamoto T, Irisa T, Noguchi Y, Sugioka Y, Iwamoto Y, et al. Increased level of apolipoprotein B/apolipoprotein A1 ratio as a potential risk for osteonecrosis. Ann Rheum Dis. 1999;58:514-6.

39. Cao K, Hong AN, Huang W, Jiang DM, Huang L. Abnormal Lipid Metabolism in Serum Disease Animal with Steroid-Induced Osteonecrosis. Acta Laboratorium Animalis Scientia Sinica. 2005;4:222-6.

40. Cao K, An H, Jiang DM. Effect of abnormal serum lipid metabolism on bone repair and reconstruction in osteonecrosis models. Chin J Clin Rehabil. 2004; 8:7952-3.

41. Yin RX, Li YY, Lai CQ. Apolipoprotein A1/C3/A5 haplotypes and serum lipid levels. Lipids Health Dis. 2010;10:1-16.

42. Villard EF, Ei KP, Frisdal E, Bruckert E, Clement K, Bonnefontrousselot D, et al. Genetic determination of plasma cholesterol efflux capacity is genderspecific and independent of HDL-cholesterol levels. Arterioscler Thromb Vasc Biol. 2013;33:822-8.

43. Ou HJ, Huang G, Liu W, Ma XL, Wei Y, Zhou T, et al. Relationship of the APOA5/A4/C3/A1 gene cluster and APOB gene polymorphisms with dyslipidemia. Genet Mol Res. 2015;14:9277-90.

44. Al-Bustan SA, Alnaqeeb MA, Annice BG, Ebrahim GA, Refai TM. Genetic association of APOB polymorphisms with variation in serum lipid profile among the Kuwait population. Lipids Health Dis. 2014;13:1-13.

Ready to submit your research? Choose BMC and benefit from:

- fast, convenient online submission

- thorough peer review by experienced researchers in your field

- rapid publication on acceptance

- support for research data, including large and complex data types

- gold Open Access which fosters wider collaboration and increased citations

- maximum visibility for your research: over $100 \mathrm{M}$ website views per year

At BMC, research is always in progress.

Learn more biomedcentral.com/submissions 